\title{
Detection of agricultural fires in the State of Acre with GEE and QGIS
}

Francisco Salatiel Clemente de Souza ${ }^{1 *}$, Sonaira S. Silval, Liana O. Anderson ${ }^{2}$, Philip M. Feanrside ${ }^{3}$, Marcus A. Liesenfeld ${ }^{l}$, Igor Oliveira ${ }^{l}$, Thiago Morello ${ }^{4}$, Adriele Karlokoski ${ }^{l}$, Tiago Lucena da Silva ${ }^{l}$, Marllus Rafael N. Almeida ${ }^{1}$, Luiz E. O. C. Aragão ${ }^{5}$, Foster Brown ${ }^{1,6}$, Jessica Costa ${ }^{1}$, Antonio Willian F. Melo $^{l}$, Paulo Maurício L. A. Graça ${ }^{1}$, Paulo M. Brando ${ }^{6,7}$, Ane Alencar $^{7}$

${ }^{1}$ Universidade Federal do Acre(Ufac), Cruzeiro do Sul, Brasil

${ }^{2}$ Centro Nacional de Monitoramento e Alertas de Desastres Naturais (Cemaden), São José dos Campos, Brasil

${ }^{3}$ Instituto Nacional de Pesquisas da Amazônia (Inpa), Manaus, Brasil

${ }^{4}$ Universidade Federal do ABC (UFABC), São Bernardo do Campo, Brasil

${ }^{5}$ Instituto Nacional de Pesquisas Espaciais (Inpe), São José dos Campos, Brasil

${ }^{6}$ Woods Hole Research Center (WHRC), Falmouth, Estados Unidos

${ }^{7}$ Instituto de Pesquisa Ambiental da Amazônia (Ipam), Brasília, Brasil

*e-mail: salatielclemente@gmail.com

ABSTRACT - Herein we aimed to test four supervised classifiers to map forest scars caused by agricultural burning activities, and also evaluate time-quality ratio accuracy. In the last decade, while deforestation rates decreased, the number of thermal hotspots increased through Amazonia. Monitoring forest burnings is important to identify and map location and trend of active burnings in real-time. However, such procedure is usually based on detection of isolated thermal hotspots on the surface, which do not allow evaluation of the size of areas affected by fire. As cloud image processing evolves and provides new tools, as Google Earth Engine (GEE), it became possible to detect and monitoring areas impacted by fire in fast and agile ways. Nevertheless, testing the efficiency of algorithms to balance commission and omission errors in the final product is pivotal. Thus, we tested four supervised classifiers (maximum likelihood, decision tree learning (CART), random forest, and minimum distance) in physical and cloud environments by the use of QGIS and GEE, respectively. We evaluate time spent (minutes) in each classification of the Landsat 8's scene 005/066, within a computer with the following configuration: Intel Core i7 processor, graphic card NVIDIA, $8 \mathrm{~Gb}$ memory RAM ddr3. We considered four classes: forest, deforestation, burnings, and bodies of water; with 20 samples for each class. Time spent with QGIS was 90 minutes: 40 minutes to download images, 13 minutes sampling the classes, and 37 minutes to obtain outputs after application of algorithm. With GEE, time spent was 27 minutes: six minutes to sampling, one minute to apply algorithm, and 20 minutes to download classification. Minimum distance was the algorithm with best performance due to minor commission and confusion errors for bodies of water and deforestation classes. Cloud image processing is a large step for digital satellite image processing routine, as it saves time and offers several classification algorithms simultaneously. Products of monitoring forest burnings are an important source of information for decision makers, supervision, and agricultural practices, as well as, inclusion in platforms as TerraMA2.

Keywords: supervised classifiers, Google Earth Engine, QGIS 